\title{
Big Data Characteristics and Innovation Performance in Ghanaian Manufacturing Firms: The Role of the Big Data Team?
}

\author{
Samuel Kofi Otchere*, Ennin Bernice Nyamewaa, Frank Hammond \\ School of Management, Jiangsu University, Jiangsu, China \\ Email: ^samme20142015@gmail.com, nyamewaaennin@gmail.com, forgeliani@gmail.com
}

How to cite this paper: Otchere, S.K., Nyamewaa, E.B. and Hammond, F. (2022) Big Data Characteristics and Innovation Performance in Ghanaian Manufacturing Firms: The Role of the Big Data Team? Open Access Library Journal, 9: e8378. https://doi.org/10.4236/oalib.1108378

Received: January 17, 2022

Accepted: February 21, 2022

Published: February 24, 2022

Copyright $\odot 2022$ by author(s) and Open Access Library Inc.

This work is licensed under the Creative Commons Attribution International License (CC BY 4.0).

http://creativecommons.org/licenses/by/4.0/

\begin{abstract}
The study scrutinizes the connection between the big data characteristics and innovation performance in selected manufacturing firms in Ghana and the mediating role of the big data team in this relationship. This provides a new perspective to the ongoing debate on the big data innovation nexus globally. Using data from 43 accidentally selected manufacturing firms from Greater Accra in a structural equation model, the study confirms that big data characteristics positively influence innovation performance in manufacturing firms. However, velocity and volume are negatively associated with innovation performance in these firms. Finally, the sophistication and skill levels of the big data team positively mediate the connection amid big data characteristics and innovation performance. Therefore, management should prioritize the employment of a highly skilled big data team to benefit from all the characteristics of big data. Further, firms should consider the long-run big data analytics benefits over the initial cost of investment.
\end{abstract}

\section{Subject Areas}

Management and Innovation

\section{Keywords}

Big Data, Big Team, Innovation, Performance, Ghana

\section{Introduction}

Businesses compete for market position, survival, and growth through product development and process reengineering [1] [2]. However, decisions regarding the specific type of product/service or processes to implement strategically de- 
pend on several factors [3]. Aside from the contribution of the internal and the external business environment to the decision-making process of businesses, big data has evolved into a critical organizational resource for innovation [4] [5]. Big data involves a large collection of structured and unstructured data which requires relatively complex analytics [6]. Businesses irrespective of location, size, or Mundus Operandi generate volumes of data daily concerning the business operations. Accordingly, the literature suggests that big data could become significant to the decisions of the business if properly managed and analyzed [7] [8] [9]. Consequently, this has attracted research inquisition concerning the role of big data analytics in the innovation performance of businesses of all sizes [10] [11]. While these studies find positive associations amid big data analytics and innovation performance, other studies suggest that the characteristics of big data (volume, velocity, variety, veracity, and value) and capabilities of the big data team could inhibit this positive association [7] [12]. Thus, this creates a research gap requiring empirical inquisition to avoid policy imbalance.

Innovation performance revolves around the ability of a business to increase the effectiveness, significance, and functionalities of new products/services, processes, or procedures [13] [14]. Therefore, businesses strive to invest in innovations capable of improving these aspects of the firm [15]. However, to meet these targets, innovations should be pursued through thorough environmental analysis, extensive market research, and big data analytics [8]. Consequently, the quality of human resources in an organization could affect the quality of information generated and the resultant innovation. Therefore, as earlier stated, the capabilities of the big data team in an organization become significant at this stage. However, existing studies by far on this phenomenon ignore big data teams' role in the link between big data analytics and innovation performance. Therefore, this study fills this gap by examining the mediating role of the big data team in the link amid big data analytics and innovation performance. The study seeks answers to the questions, what is the relationship between the big data characteristics and innovation performance? And does the big data team mediate the relationship between big data characteristics and firm performance? The big data characteristics involve big data (volume, velocity, variety, veracity, and value). Innovation performance also focuses on product innovation performance.

The study focuses on manufacturing firms in Ghana because these groups of firms are constantly faced with the challenge of introducing new products, cost-cutting processes, and procedures to ensure sustainability. Further, this market is relatively saturated so customers seek superior products at relatively cheaper prices to maintain their loyalty to a specific brand. Therefore, to remain competitive in this saturated market, these firms must improve innovation performance. Employing survey data from 43 manufacturing firms in the Greater Accra region of Ghana and using structural equation model, the study reveals that big data analytics influences innovation performance in manufacturing firms. Further, the 
sophistication of the big data team mediates the link between big data analytics and innovation performance. Therefore, the study adds extensively to the existing literature on big data and innovation nexus.

Several studies examine the relationship between big data and the innovation performances of firms of all sizes. While some of the findings from these studies are synonymous with the current study, others contradict. Table 1 provides a

Table 1. Summary of state of the art.

\begin{tabular}{|c|c|c|c|}
\hline Author & Focus & Method(s) & outcome \\
\hline $\begin{array}{l}\text { Trabucchi \& Buganza } \\
{[10] \text {. }}\end{array}$ & Data-driven innovation & $\begin{array}{l}\text { Exploratory multiple case } \\
\text { study analysis }\end{array}$ & Big data drives innovation in firms \\
\hline Bresciani et al. [16]. & $\begin{array}{l}\text { Big data and } \\
\text { co-innovation }\end{array}$ & Systematic literature review & $\begin{array}{l}\text { Big data and intentional } \\
\text { collaborations with external } \\
\text { parties drives innovation }\end{array}$ \\
\hline Babu et al. [11]. & Data-driven innovation & Systematic literature review & $\begin{array}{l}\text { The seven data-driven innovation } \\
\text { steps are significant to innovation }\end{array}$ \\
\hline Lerena et al. [17]. & $\begin{array}{l}\text { Big data and innovation } \\
\text { at the firm level }\end{array}$ & $\begin{array}{l}\text { Social Network Analysis and } \\
\text { Text Mining techniques }\end{array}$ & $\begin{array}{l}\text { There exist multiple and } \\
\text { heterogeneous dimensions in } \\
\text { firm-level data mining }\end{array}$ \\
\hline $\begin{array}{l}\text { Ghasemaghaei \& } \\
\text { Calic [7]. }\end{array}$ & $\begin{array}{l}\text { Big data's main } \\
\text { characteristics and } \\
\text { innovation performance }\end{array}$ & Structural Equation Model & $\begin{array}{l}\text { Data velocity is significant in firm } \\
\text { innovation performance compared to } \\
\text { other big data characteristics }\end{array}$ \\
\hline Wright et al. [8]. & $\begin{array}{l}\text { Big data in innovation } \\
\text { and market leadership in } \\
\text { B2B relationships }\end{array}$ & Conceptual and Case studies & $\begin{array}{l}\text { Big data represents organizations' } \\
\text { ability to respond to market } \\
\text { opportunities through innovation }\end{array}$ \\
\hline Niebel et al. [19]. & $\begin{array}{l}\text { Big data analytics and } \\
\text { product innovation } \\
\text { performance }\end{array}$ & $\begin{array}{l}\text { Knowledge production } \\
\text { function framework }\end{array}$ & $\begin{array}{l}\text { Big data analytics stimulates } \\
\text { innovation }\end{array}$ \\
\hline $\begin{array}{l}\text { Mikalef \& Krogstie, } \\
\text { [18]. }\end{array}$ & $\begin{array}{l}\text { Big data, contextual } \\
\text { factors, and firm } \\
\text { performance }\end{array}$ & Grounded Theory & $\begin{array}{l}\text { Diverse blends of contextual factors } \\
\text { affect the significance of big data } \\
\text { analytics }\end{array}$ \\
\hline Mikalef et al. [9]. & $\begin{array}{l}\text { Big data, dynamic } \\
\text { capabilities, and firm } \\
\text { performance }\end{array}$ & Structural Equation Model & $\begin{array}{l}\text { Big data affect dynamic competencies } \\
\text { while incremental innovation } \\
\text { capability is enhanced through a } \\
\text { sequence }\end{array}$ \\
\hline $\begin{array}{l}\text { Ghasemaghaei \& } \\
\text { Calic, [12]. }\end{array}$ & $\begin{array}{l}\text { Big data characteristic on } \\
\text { firm innovation }\end{array}$ & Grounded Theory & $\begin{array}{l}\text { Data velocity, variety, and veracity } \\
\text { enhance data-driven insight } \\
\text { generation than data volume }\end{array}$ \\
\hline Lozada et al. [20]. & Big data and innovation & Structural Equation Model & $\begin{array}{l}\text { Big data analytics promotes } \\
\text { responsive processes of product } \\
\text { and service co-creation }\end{array}$ \\
\hline Prester \& Jurić, [6]. & $\begin{array}{l}\text { Big data and product } \\
\text { innovation }\end{array}$ & Ordinary Least Square & $\begin{array}{l}\text { Some sources of big data are } \\
\text { significant while others are not }\end{array}$ \\
\hline
\end{tabular}


summary of some selected studies examining this phenomenon. Trabucchi and Buganza [10] using multiple case studies confirms that big data analytics promotes positive firm innovation. Bresciani et al. [16] in a systematic review suggest that big data analytics and intentional firm collaboration drives firm innovation. This study combines all the elements of big data characteristics without differentiation. However, Babu et al. [11] also identify that the seven steps in data-driven innovation are significant to the innovation performance of a firm. Lerena et al. [17] found that there exist different levels of data mining in big data and thus these heterogenous levels could affect innovation. Again, Ghasemaghaei \& Calic [7] suggest that although other characteristics of big data are significant, velocity is more critical to innovation. These studies focus on the different characteristics of big data and the consequential effect on innovation. Per Wright et al. [8], big data could provide a clue to the innovation drive of a firm. Further, other studies all find a positive association between big data and innovation performance in different classes of businesses [6] [9] [12] [18] [19] [20]. Thus, our study contributes to data by focusing on the different big data characteristics and the performance of manufacturing firms in Ghana by considering the mediating role of the big data team.

Figure 1 describes the connections amongst the variables. Per the subject under discussion, the study's theoretical model is built following appropriate literature review in Table 1 illustrated in Figure 1. This depicts the associations between big data characteristics, innovation performance, and big data team. Two research hypotheses are developed to verify the relationships between the variables. We expect the various big data characteristics to positively influence innovation performance in these SMEs. Further, although these characteristics are expected to influence innovation performance, we also propose that the strength of these relationships could be explained by the quality of the big data team in the SMEs.

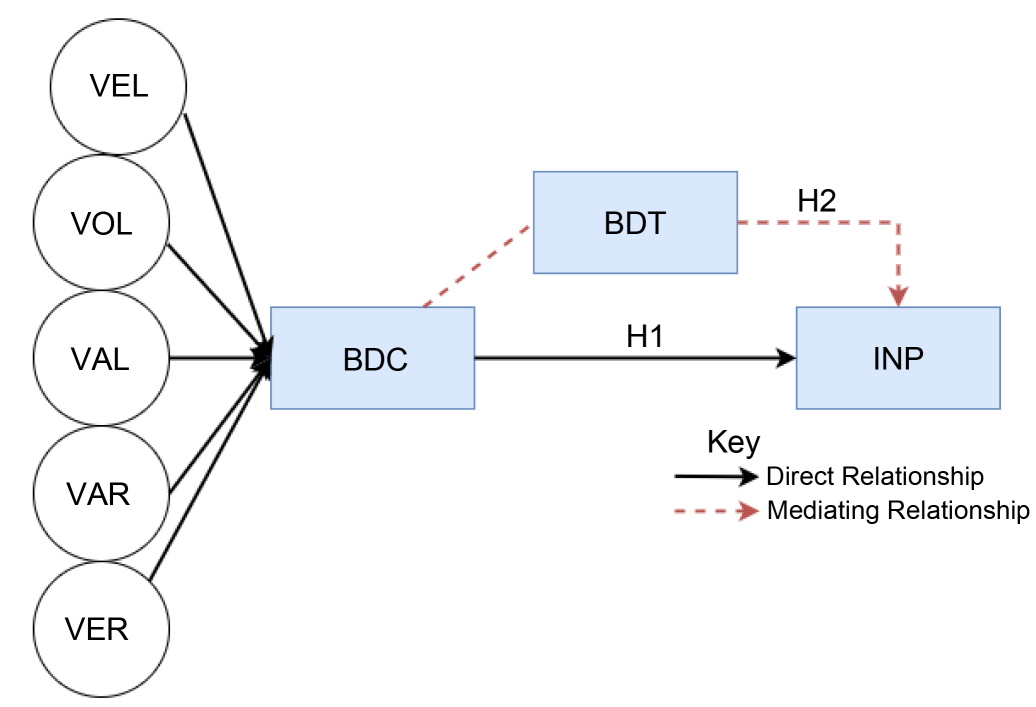

Figure 1. Conceptual framework. 
Hypothesis H1. Big data characteristics positively influence innovation performance in manufacturing firms.

Hypothesis H2: Big data team mediates the relationship between innovation performance and big data characteristics in manufacturing firms.

\section{Research Methodology}

The study employs a descriptive research approach to gauge the association amid big data characteristics and innovation performance in the selected Ghanaian manufacturing firms. Manufacturing firms are preferred over service firms because of the need to differentiate products to satisfy the needs of customers. The study focuses mainly on manufacturing firms in the Greater Accra Region of Ghana. In all, there are dozens of such businesses, however, most of these businesses were unwilling to partake in the survey so the non-probability accidental sampling technique was employed to include firms that are willing. In all, 64 firms were included in the study as the sample. The study surveyed the chief executive officers of these firms. This is because they are considered individuals responsible for the overall direction of the firm. The data was collected using a survey questionnaire. First, questionnaires were piloted to eliminate errors and ambiguity. After, the survey instrument was edited to suit the purpose of the study. The overall data collection period lasted between May, 2021-August, 2021. Table 2 provides details of the survey instrument design and the corresponding sources. The big data characteristics include velocity, volume, value, variety, and veracity [6] [12]. The innovation performance measures new product introduction and the market outcome of the products [13] [14] [18]. Finally, the big data team measures the team's sophistication, diversity, and agility [18] [19]. The final survey produced 43 duly completed responses. These responses were cleaned, coded, and analyzed using smart PLS software.

Table 2. Construct development.

\begin{tabular}{cccc}
\hline Constructs & Elements & Items & References \\
\hline & Velocity & 4 questions & Prester \& Jurić [6], Ghasemaghaei \& Calic [12] \\
Volume & 4 questions & Prester \& Jurić [6], Ghasemaghaei \& Calic [12] \\
Big Data & Value & 4 questions & Prester \& Jurić [6], Ghasemaghaei \& Calic [12] \\
& Variety & 4 questions & Prester \& Jurić [6], Ghasemaghaei \& Calic [12] \\
& Veracity & 4 questions & Prester \& Jurić [6], Ghasemaghaei \& Calic [12] \\
\hline \multirow{2}{*}{ Innovation Performance } & New Products & 3 questions & Martínez-Noya \& García-Canal [13] \\
& Market outcome & 3 questions & Rauter et al. [21] \\
\hline Big Data Team & Sophistication & 3 questions & Niebel et al. [19], Mikalef \& Krogstie [18] \\
& Diversity & 3 questions & Niebel et al. [19], Mikalef \& Krogstie [18] \\
& Agility & 3 questions & Niebel et al. [19], Mikalef \& Krogstie [18]
\end{tabular}

Source: Authors construct. 


\section{Model Specification}

Per the study problem, objective, and questions, the result of these can best be assessed with a series of regression models. Therefore, we employ the structural equation model (SEM) comparable to existing literature (Lozada et al.), [18] [20] to estimate the association between big data characteristics (BDC), innovation performance (INP), and big data team (BDT). The model supports the estimation of multifaceted relations between one or more independent variables as well as one or more dependent variables. This statistical technique allows the assessment of multilevel regression models and is applied to testing research hypotheses with direct and indirect observations of one or more dependent and independent variables. The main reason for adopting this technique in this study is to help assess the relationship between the variables and validate the proposed causal models. Accordingly, BDC is the response variable $(Y)$ while INP is an exogenous variable with $\mathrm{BDT}$ as the mediating variable. The model is presented hypothetically in a matrix form as:

$$
\left[\begin{array}{c}
y_{1} \\
\vdots \\
y_{p}
\end{array}\right]=\left(\begin{array}{ccc}
0 & \cdots & \beta_{1 p} \\
\vdots & \ddots & \vdots \\
\beta_{p 1} & \cdots & 0
\end{array}\right)\left[\begin{array}{c}
y_{1} \\
\vdots \\
y_{p}
\end{array}\right]+\left(\begin{array}{ccc}
\delta_{11} & \cdots & \delta_{1 q} \\
\vdots & \ddots & \vdots \\
\delta_{p 1} & \cdots & \delta_{p q}
\end{array}\right)\left[\begin{array}{c}
x_{1} \\
\vdots \\
x_{q}
\end{array}\right]+\left[\begin{array}{c}
\varepsilon_{1} \\
\vdots \\
\varepsilon_{p}
\end{array}\right]
$$

In Summary, the matrix equation in Equation (1) is reformulated as:

$$
Y=\boldsymbol{B} Y+\Gamma X+\varepsilon
$$

where $p$ symbolizes the regression equations to be assessed concurrently, $p$ by $p$ $\boldsymbol{B}$ square matrix encompasses the parameter coefficients of the regressors of $Y$ variables on the other $Y$ variables with the 0 diagonal values denoting that a variable cannot influence itself. Furthermore, the $p$ by $q \Gamma$ matrix contains coefficients of the $Y$ s on $X$ s whereas $\varepsilon$ is a $p$ by 1 vector consisting of residual terms. Grounded on the theoretical model specification, reasoning can be made that a number of regression Equations (3) are to be estimated to gauge the causal effects amid the variables employed in the study as indicated in Equations (3a) and (3b). First, Equation (3a) considers the relationship between the big data teams (BDC) and innovation performance (INP) in the SMEs as previously examined by key studies [6] [17].

$$
\mathrm{BDC}_{i}=\beta_{0}+\beta_{a} \mathrm{INP}+\varepsilon_{i}
$$

Next, given the critical role of big data teams in big data analytics, Equation (3b) considers the mediating role of big data team (BDT) in the relationship between big data characteristics and innovation performance as previously tested in other studies [12] [20].

$$
\mathrm{BDC}_{i}=\beta_{0}+\beta_{b} \mathrm{BDT}^{*}+\beta_{a} \mathrm{INP}+\varepsilon_{i}
$$

\section{Empirical Estimation}

\subsection{Multicollinearity Test}

Before estimating the model, it is important to examine if the variables under 
consideration have no issues of collinearity, Therefore, following the study of Cephasetal., [21], we review the probability of multicollinearity between the variables using the variance inflation factor (VIF). Given the acceptance or rejection of the null hypothesis benchmark, values of the VIF must not exceed 10.00. These values are automatically estimated with the SmartPLS. Consequently, given the output in Table 3, the null hypothesis of the existence of multicollinearity is rejected because all the values reported are within 10.00 bound. Thus, we can proceed to estimate the final structural equation model.

\subsection{Construct's Reliability and Validity Tests}

The study employs a sequence of tests to examine the reliability and validity of the study constructs. See Table 4 for details of the test results. These tests are necessary to satisfy the conditions for the estimation of the final structural model depicted in Figure 1. Accordingly, the Herman Single Factor, B-S test, KMO and Bartlett's test, the Cronbach alpha, factor loadings, and the Eigen-value are employed. Per the Herman Single factor test via the principal axis factoring (PAF), the value of $35.43 \%$ indicates that a single factor is an issue in the study because the value is less than $50 \%$. The Cronbach's alpha proves that the research instrument is internally consistent with values above 0.80 . The KMO and Bartlett's test proves that the sampling is adequate. Again, the validity of the research instrument is measured using the average variance extracted (AVE). The outcome shows cross-loadings of above 0.8 respectively to support this assertion. Since the AVE values are expected to be 0.50 or above to suggest that the research instrument fits the requirements for reliability and validity.

Table 3. Collinearity statistics (VIF).

\begin{tabular}{cl}
\hline Items & VIF \\
\hline BDC & 3.90 \\
INP & 2.51 \\
BDT & 3.45 \\
BDC $^{\star}$ INP & 2.95 \\
BDC $^{\text {BDT }}$ & 3.71 \\
BDC $^{*} \mathrm{BDT}^{\star}$ INP & 3.91 \\
\hline
\end{tabular}

${ }^{\star}$ Note: VIF (Variance Inflation Factor).

Table 4. Construct reliability and validity.

\begin{tabular}{ccccccccc}
\hline Factors & $\begin{array}{c}\text { Factor } \\
\text { loads }\end{array}$ & Eigen-value & $\begin{array}{c}\text { Cum } \% \\
\text { variance } \\
\text { explained }\end{array}$ & $\begin{array}{c}\text { Cronbach } \\
\boldsymbol{\alpha}\end{array}$ & AVE & $\begin{array}{c}\text { KMO } \\
\text { test }\end{array}$ & $\begin{array}{c}\text { B-S } \\
\text { test }\end{array}$ & HMS \\
\hline BDC & 0.96 & 3.31 & 87.24 & 0.86 & 0.98 & 0.83 & $3060.60 \mathrm{a}$ & \\
BDT & 0.85 & 3.11 & 92.75 & 0.94 & 0.88 & 0.82 & $3604.34 \mathrm{a}$ & $35.43 \%$ \\
INP & 0.92 & 3.52 & 85.23 & 0.94 & 0.89 & 0.81 & $3577.34 \mathrm{a}$ & \\
\hline
\end{tabular}

${ }^{\star}$ Note: a represents a $1 \%$ level of significance. 


\subsection{Discriminant Validity}

After ascertaining the reliability and validity of the investigation instrument. the discriminant validity of the instrument is examined. See Table 5 for details of the results. The Fornell-larcker criterion and the Heterotrait-Monotriat Ration (HTMT) are employed. The Fornell-Larcker test corroborates that the research instruments are not identical with values not exceeding 0.85 . This is consistent with the suggestion of Henseler et al. [22].

The Heterotrait-Monotriat Ratio is employed to estimate and validate the discriminant validity established by the Fornell-Larcker Criterion. See Table 6 for details of the results. Per Clark and Watson [23], the threshold should be 0.85 . However, Teo et al. [24] also recommend a tolerance correlation threshold of 0.90. Per the results, all the constructs fall within the acceptable thresholds. This indicates by the Fornell-Larcker Criterion, the HTMT ratio also endorses that the constructs are unrelated.

\subsection{Structural Model Analysis}

The study explores the association between big data, innovation performance, and the mediating role of the big data team. Appropriately, the path approximation and the p-value $(<0.05)$ provide the basis for the acceptance or rejection of the study hypothesis. See Table 7 and Figure 2 for details of the results. The relationship between big data characteristics and innovation performance in manufacturing firms is positive. This is supported by a path coefficient of 0.45 and a statistically significant value of $0.02 \mathrm{a}$. However, two of the big data characteristics (velocity and volume) show negative effects. This suggests that although the big data characteristics influence innovation performance in the manufacturing firms, only value, variety, and veracity have positive effects. Further, the outcomes show that the big data team positively mediates the relationship between

Table 5. Fornell-Larcker criterion.

\begin{tabular}{ccccc}
\hline & BDC & BDT & Mediating Effect & INP \\
\hline BDC & 0.82 & & & \\
BDT & -0.37 & 0.77 & & \\
Moderating Effect & -0.41 & 0.17 & 0.84 & \\
INP & -0.12 & 0.73 & 0.27 & 0.83 \\
\hline
\end{tabular}

Table 6. Heterotrait-Monotriat Ratio (HTMT).

\begin{tabular}{ccccc}
\hline & BDC & BDT & Mediating Effect & INP \\
\hline BDC & & & \\
BDT & 0.16 & & \\
Moderating Effect & 0.35 & 0.07 & \\
INP & 0.06 & 0.83 & 0.06 \\
\hline
\end{tabular}

*Note: BDD (Big Data), BDT (Big Data Team), and INP (Innovation Performance). 
the big data characteristics and innovation performance in manufacturing firms. This is supported by a path coefficient of 0.56 and a statistically significant value of 0.03a. Statistically, the relationship between the big data characteristics and innovation performance increases in strength with the introduction of the mediating variable (big data team).

The model robustness is established to determine the performance of the model over an empty model. Thus, we engage the R2 and the adjusted R2 and, Q2 respectively. See Table 8 for details of the results. Accordingly, the result suggests that the model performs more than $90 \%$ better than a zero model. Further, the F-statistics supports this declaration with values of more than 0.05 .

Table 7. Structural equation model output.

\begin{tabular}{cccc}
\hline Direct Relationships & Path coefficients & P. Value & Decision \\
\hline BDC-INP & 0.45 & $0.02 \mathrm{a}$ & Supported \\
BDC-BDT-INP & 0.56 & $0.03 \mathrm{a}$ & Supported \\
\hline VEL-INP & Indirect relationships & & \\
VOL-INP & -0.09 & $0.03 \mathrm{a}$ & Unsupported \\
VAL-INP & -0.12 & $0.02 \mathrm{a}$ & Unsupported \\
VAR-INP & 0.31 & $0.04 \mathrm{a}$ & Supported \\
VER-INP & 0.09 & $0.00 \mathrm{a}$ & Supported \\
\hline
\end{tabular}

Note: a denotes statistical significance at $5 \%$.

Table 8. Predictive relevance.

\begin{tabular}{cccc}
\hline Construct & R square & Adjusted R square & Q square \\
\hline INP & 0.87 & 0.92 & 0.79 \\
\hline \multicolumn{3}{c}{ F-Square } \\
\hline INP \\
\hline Mediating Effect & 0.56 & Strong \\
\hline
\end{tabular}

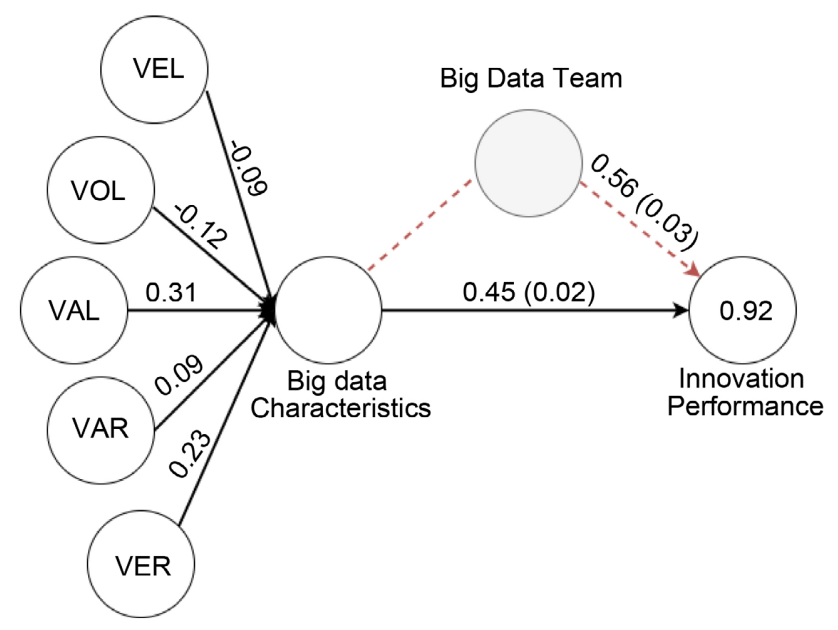

Figure 2. The output of the model estimation. 


\section{Discussion}

The study reconnoiters the association amid big data characteristics and innovation performance in manufacturing firms in Ghana. Further, it examines the mediating role of the big data team in the association between big data characteristics and innovation performance.

Big data characteristics positively influence innovation performance in manufacturing firms. This is consistent with existing studies [10] [11] [16] to indicate the significance of big data analytics in the innovation activities of firms of all sizes. Management should invest in advanced data analytics software which provides cutting-edge analytics to support the innovation agenda of the firm. This also challenges firms not investing enough into big data analytics in Ghana to consider the sustainable significance of big data analytics over the initial cost of investment. Further, aside from big data analytics, management should endeavor to engage other parties like customers and other firms as suggested by Bresciani et al. [16]. This is because these sources of innovation also contribute a rich source of data that may not be made available to a firm through only big data analytics.

Value, variety, and veracity are positively linked with innovation performance in the manufacturing firms while velocity and volume are negatively linked with the innovation performance of the firms. While it is expected that all these characteristics positively affect the innovation performance of firms, other studies [6] [12] also identify differences in the contribution of these characteristics to innovation performance. This difference could be explained by the sources of the data as well as the sophistication of the big data team. Therefore, firms should expand the sources of big data by including both internal and external sources of data. Further, the firms should employ big data teams with the necessary skills to exploit all the characteristics of big data to improve innovation performance. This is because all these five big data characteristics have significant contributions to innovation if properly harnessed.

Finally, big data team positively mediates the association between big data characteristics and innovation performance in manufacturing firms. This is coherent with the outcome of existing studies [8] [19] to show that the qualification and sophistication of the big data team in a firm has a significant role in the innovation performance of firms. Theoretically, the absence of a big data team means a firm cannot utilize big data analytics in decision-making. However, the skill level and sophistication of the big data team would determine the extent of analytics performed to support the decision of the firm. Therefore, the management of firms should strategically recruit individuals with the prerequisite knowledge in big data analytics. Again, management should design training and development programs to constantly update the knowledge and skill levels of the big data team to promote industry best practices.

\section{Conclusions}

The study examines the model (big data characteristics, innovation performance, 
and big data team) after performing multicollinearity checks, reliability tests, and validity tests to ensure the robustness of the results. Therefore, the conclusion of the study is grounded on the robust outcome of the model.

The study confirms that big data characteristics positively influence innovation performance in manufacturing firms in Ghana. This is because the decision-making process of firms is supported by rich data/information availability. Therefore, big data analytics provides a good source of data for these businesses. Consequently, this challenges firms in Ghana to invest in big data analytics to provide real-time data for decision-making quality. Firms looking to compete in today's competitive business environment cannot ignore the significance of big data and thus should consider big data analytics in decision making irrespective of the initial estimated cost involved.

Further, the study establishes that value, variety, and veracity are positively connected with innovation performance in manufacturing firms. On the other hand, velocity and volume are negatively connected with the innovation performance of the firms. While all the five big data characteristics are significant to the quality of analytics generated, this outcome could be explained by the skill level or the sophistication level of the big data team available in the firms. Therefore, because the best of big data analytics is achieved through these five distinct characteristics, the management of these firms should institute strategic human resource plans to recruit and select highly skilled big data teams to achieve optimum data analytics results for improved innovation performance.

Finally, big data team positively mediates the connection between big data characteristics and innovation performance in manufacturing firms. While the relationship between big data and innovation is established, big data team sophistication and skill level provide the needed missing piece of the jigsaw puzzle. This suggests that management should prioritize the quality of the big data team if they desire to achieve optimum results. In Ghana, most businesses are small or medium in size and thus financial constraints could inhibit their decisions to invest in big data analytics. However, in the long run, these businesses would benefit from big data analytics if investments are made strategically.

\section{Limitations and Recommendations for Future Studies}

The study adds to the existing literature on the linkage between big data analytics and innovation performance in businesses. Although this is timely, it has a few limitations that could be improved in future studies. First, the study focuses only on the capital city of Ghana and thus excludes businesses in the rural areas. Future studies should consider this class of businesses to examine the difference in business location. Finally, the study focuses on manufacturing firms using the structural equation model and thus ignores other classes of businesses. Future studies should consider other classes of businesses with different estimation methods. 


\section{Conflicts of Interest}

The authors declare no conflicts of interest.

\section{References}

[1] Breus, S., Bielialov, T., Denysenko, M., Zarichniak, A. and Al-Tmeizi, A. (2019) Strategic Management of Deployment of Innovation Projects at the Enterprise. Academy of Strategic Management Journal, 18, 1-5. https://er.knutd.edu.ua/handle/123456789/15304

[2] Liu, W. and Atuahene-Gima, K. (2018) Enhancing Product Innovation Performance in a Dysfunctional Competitive Environment: The Roles of Competitive Strategies and Market-Based Assets. Industrial Marketing Management, 73, 7-20. https://doi.org/10.1016/j.indmarman.2018.01.006

[3] Hensmans, M. (2021) The Innovation Pyramid: Five Approaches to Strategic Decision-Making. Journal of Business Strategy.

https://doi.org/10.1108/JBS-12-2020-0292

[4] Grant, E. (2021) Big Data-Driven Innovation, Deep Learning-Assisted Smart Process Planning, and Product Decision-Making Information Systems in Sustainable Industry 4.0. Economics, Management, and Financial Markets, 16, 9-19. https://doi.org/10.22381/emfm16120211

[5] Capurro, R., Fiorentino, R., Garzella, S. and Giudici, A. (2021) Big Data Analytics in Innovation Processes: Which Forms of Dynamic Capabilities Should Be Developed and How to Embrace Digitization? European Journal of Innovation Management. https://doi.org/10.1108/EJIM-05-2021-0256

[6] Prester, J. and Glasnik, M.J.-T. (2019) Big Data for Product Innovation in Manufacturing: Evidence from a Large-Scale Survey. Tehnički Glasnik, 13, 36-42. https://doi.org/10.31803/tg-20181011124610

[7] Ghasemaghaei, M. and Calic, G. (2020) Assessing the Impact of Big Data on Firm Innovation Performance: Big Data Is Not Always Better Data. Journal of Business Research, 108, 147-162.

https://www.sciencedirect.com/science/article/pii/S0148296319305740

[8] Wright, L.T., Robin, R., Stone, M. and Aravopoulou, D.E. (2019) Adoption of Big Data Technology for Innovation in B2B Marketing. Journal of Business-to-Business Marketing, 26, 281-293. https://doi.org/10.1080/1051712X.2019.1611082

[9] Mikalef, P., Boura, M., Lekakos, G. and Krogstie, J. (2019) Big Data Analytics Capabilities and Innovation: The Mediating Role of Dynamic Capabilities and Moderating Effect of the Environment. British Journal of Management, 30, 272-298. https://doi.org/10.1111/1467-8551.12343

[10] Trabucchi, D. and Buganza, T. (2019) Data-Driven Innovation: Switching the Perspective on Big Data. European Journal of Innovation Management, 22, 23-40. https://doi.org/10.1108/EJIM-01-2018-0017

[11] Babu, M.M., Rahman, M., Alam, A. and Dey, B.L. (2021) Exploring Big Data-Driven Innovation in the Manufacturing Sector: Evidence from UK Firms. Annals of Operations Research, 1-28. https://doi.org/10.1007/s10479-021-04077-1

[12] Ghasemaghaei, M. and Calic, G. (2019) Does Big Data Enhance Firm Innovation Competency? The Mediating Role of Data-Driven Insights. Journal of Business Research, 104, 69-84.

https://www.sciencedirect.com/science/article/pii/S0148296319304138

[13] Martínez-Noya, A. and García-Canal, E. (2021) Innovation Performance Feedback 
and Technological Alliance Portfolio Diversity: The Moderating Role of Firms' R\&D Intensity. Research Policy, 50, Article ID: 104321.

https://doi.org/10.1016/j.respol.2021.104321

[14] Rauter, R., Globocnik, D., Perl-Vorbach, E. and Baumgartner, R.J. (2019) Open Innovation and Its Effects on Economic and Sustainability Innovation Performance. Journal of Innovation \& Knowledge, 4, 226-233. https://doi.org/10.1016/j.jik.2018.03.004

[15] Hameed, W.U., Basheer, M.F., Iqbal, J., Anwar, A. and Ahmad, H.K. (2018) Determinants of Firm's Open Innovation Performance and the Role of R \& D Department: An Empirical Evidence from Malaysian SME's. Journal of Global Entrepreneurship Research, 8, 29. https://doi.org/10.1186/s40497-018-0112-8

[16] Bresciani, S., Ciampi, F., Meli, F. and Ferraris, A. (2021) Using Big Data for Co-Innovation Processes: Mapping the Field of Data-Driven Innovation, Proposing Theoretical Developments and Providing a Research Agenda. International Journal of Information Management, 60, Article ID: 102347.

https://www.sciencedirect.com/science/article/pii/S0268401221000402 https://doi.org/10.1016/j.ijinfomgt.2021.102347

[17] Lerena, O., et al. (2019) Big Data of Innovation Literature at the Firm Level: A Review Based on Social Network and Text Mining Techniques. Economics of Innovation and New Technology, 30, 134-150. https://doi.org/10.1080/10438599.2019.1684646

[18] Mikalef, P. and Krogstie, J. (2020) Examining the Interplay between Big Data Analytics and Contextual Factors in Driving Process Innovation Capabilities. European Journal of Information Systems, 29, 260-287. https://doi.org/10.1080/0960085X.2020.1740618

[19] Niebel, T., Rasel, F. and Viete, S. (2018) BIG Data-BIG Gains? Understanding the Link between Big Data Analytics and Innovation. Economics of Innovation and New Technology, 28, 296-316. https://doi.org/10.1080/10438599.2018.1493075

[20] Lozada, N. and Arias-Pérez, J. (2019) Big Data Analytics Capability and Co-Innovation: An Empirical Study. Heliyon, 5, e02541.

https://www.sciencedirect.com/science/article/pii/S2405844019362012

[21] Coffie, C.P.K., Mensah, I.A., Kiconco, R., Simon, A.E.O., et al. (2020) Determinants of FinTech Payment Services Diffusion by SMEs in Sub-Saharan Africa: Evidence from Ghana. Information Technology for Development, 27, 539-560. https://doi.org/10.1080/02681102.2020.1840324

[22] Henseler, J. and Ringle, C. (2015) A New Criterion for Assessing Discriminant Validity in Variance-Based Structural Equation Modeling. Journal of the Academy of Marketing Science, 43, 115-135. https://link.springer.com/article/10.1007\%252Fs11747-014-0403-8

[23] Clark, L.A. and Watson, D. (2019) Constructing Validity: New Developments in Creating Objective Measuring Instruments. Psychological Assessment, 31, 1412-1427. https://doi.org/10.1037/pas0000626

[24] Teo, T.S.H., Srivastava, S.C. and Jiang, L. (2008) Trust and Electronic Government Success: An Empirical Study. Journal of Management Information Systems, 25, 99-132. https://doi.org/10.2753/MIS0742-1222250303 